\title{
Emotional instability trait of personality and different levels of employment status among youth
}

\author{
Brijesh Kumar Upadhayay \\ Department of Computer Science, Uttarakhand Sanskrit University, Haridwar, Uttarakhand, India
}

Email address:

upbrijesh@gmail.com

\section{To cite this article:}

Brijesh Kumar Upadhayay. Emotional Instability Trait of Personality and Different Levels of Employment Status among Youth. Psychology and Behavioral Sciences. Vol. 3, No. 4, 2014, pp. 121-125. doi: 10.11648/j.pbs.20140304.13

\begin{abstract}
The present paper is a modest attempt to study the emotional instability trait of personality among different levels of employment status in youth within the age group of 26 to 35 years. The sample is of a scattered in nature and a list of youths is prepared from the Haridwar district of Uttarakhand, India. The total sample consisting of 200 youth selected through cluster random sampling. The Dimensional Personality Inventory (DPI), Bhargava M. (1997) tools was used to find out the emotional instability trait of personality in youth. The results indicate that female youth are less emotional stable rather than male youth in general.
\end{abstract}

Keywords: Emotional Stability, Emotional Instability, Personality, Personality Trait, Unemployment, Employment, Seasonally Unemployed, Frictionally Unemployed

\section{Introduction}

The effects of unemployment may also have a more generalized influence on the psychological health of populations; that is, the unemployment rate, not necessarily the individual experience of unemployment, could be indirectly responsible for individual psychological illhealth. For example, high level of unemployment can force more people to accept unfavourable working conditions or jobs they would rather not do.

In this paper we are using different levels of employment status like frictionally unemployment, seasonally unemployment, fully unemployment, fully employment. Frictionally unemployment involves people being temporarily between jobs, searching for new ones. It arises because either employers fire workers or workers quit, usually because the individual characteristics of the workers do not fit the individual characteristics of the job (including matters of the employer's personal taste or the employee's inadequate work effort). Seasonal unemployment might be seen as a kind of structural unemployment, since it is a type of unemployment that is linked to certain kinds of jobs (construction work, migratory farm work). The most-cited official unemployment measures erase this kind of unemployment from the statistics using "seasonal adjustment" techniques. Some economists posit the existence of a natural rate of unemployment or a NAIRU at full employment, which means that if the unemployment rate gets "too low," inflation will get worse and worse (accelerate) in the absence of the wage and the price controls (incomes policies). Others simply see the possibility of inflation rising as the unemployment rate falls. Fully unemployment mean that the person who does not have any job to survive ${ }^{[6]}$.

Unemployment happens to many persons and can be a stressful, depressing and guilt ridding time of life. Unemployment is a reality for many young people. You may be skilled, qualified, willing to work, ready for work and desperately wanting for a job, but for many young person it does not guarantee you will get work, because in many places there just are not enough jobs around for everyone.

The emotional instability trait of personality indicates emotional instability where individual is affected by the feelings, emotionally less stable, easily annoyed and upset having low frustration tolerance for unsatisfactory conditions, highly anxious and worrying, fearful, sensitive, touchy, given to mood swings, depressed and sad whenever confronted with stressful situations, having neurotic symptoms like phobias, sleep disturbances and psychotic disorders. The indicative mode of emotionally stable trait of the personality where person is, with control over his emotional expressions, emotionally mature, stable, realistic 
about life situations, possessing ego strength, high level of adjustment with unsolved emotional problems.

\section{Materials and Methods}

\subsection{Subjects}

The scale of Dimensional Personality Inventory test were administered over these 330 youth and 200 of these have been selected through clustered random sampling from the list of youth prepared with the help of employment exchange within the age group of 26 to 35 years, belonging to middle socio-economic status are selected from Haridwar district of Uttarakhand. Due weight was assigned to their Employment status (fully employed, fully unemployed, seasonally unemployed, frictionally unemployed), sex constitution. For the purpose of sensitivity, control and precision, the study has adopted $2 \times$ 4 bivariate factorial experiment in the study. The bivariate factorial design has rendered a natural setting to variate operations and has provided an opportunity to study interactions.

Table 1. Indicate Distribution of Subject in Paradigm.

\begin{tabular}{|c|c|c|c|c|c|c|}
\hline & & \multicolumn{4}{|c|}{ Employment Status } & \multirow{2}{*}{$\Sigma$} \\
\hline & & Fully Employed & Fully Unemployed & Seasonally Unemployed & Frictionally Unemployed & \\
\hline \multirow{2}{*}{ Sex } & Male & 25 & 25 & 25 & 25 & 100 \\
\hline & Female & 25 & 25 & 25 & 25 & 100 \\
\hline$\sum$ & & 50 & 50 & 50 & 50 & 200 \\
\hline
\end{tabular}

\subsection{Variables}

\subsubsection{Independent Measure}

A. Employment Status: Employment status of youth is taken for study as independent measure with four different status of 1-regular employed, 2-fully unemployed, 3-frictionally unemployed, 4seasonally unemployed.

B. Sex: Gender of the youths as male and female are taken another independent measure of the present investigation.

\subsubsection{Dependent Measure}

Emotional Stability-Instability trait of personality.

\subsection{Tools}

Dimensional Personality Inventory (DPI), Bhargava M.( 1997).

It consists of 60 statements in simple Hindi/ English. It measures six important personality dimensions - ActivityPassivity, Enthusiastic-Non-enthusiastic, AssertiveSubmissive, Suspicious-Trusting, Depressive-Non-depressive, Emotional Instability-Emotional Stability. Each personality trait is measured by 10 items through three response alternatives-Yes, Undecided and No.

\subsection{Administration and Scoring}

This test may be administered on all individuals regardless to sex above the age of 14 years. It can be used individually as self administration as well as in group also. It can be used by the test administrator by taking verbal response alternative on those who cannot read and so depleted by illness.

\subsection{Scoring and Interpretation}

Each yes response is to be scored as 2, undecided is to be scored as 1 where as no and unmarked response it to be scored as zero. All the six dimensional area of personality are grouped as part I, II, III, IV, V and VI each containing 0 to 20 and thus may be calculated area wise and total score of each part may be obtained at that place and then transfer to scoring table below each part against raw scores column.

\subsection{Procedure}

Emotional stability-instability trait of personality were administered over these 330 youth and 200 of these have been selected through clustered random sampling from the list of youth prepared with the help of employment exchange within the age group of 26 to 35 years, belonging to middle socio-economic status are selected from Haridwar. Subjects are divided in eight equal parts as per our research paradigm. Research scholar gets 25 subjects in each group. The prescribed DPI test has been applied to the experimental group. After getting value of DPI test research scholar applied statistical tool to get result.

\subsection{Statistical Analysis}

The statistical techniques used for analyzing the data were Anova and Duncan's Multiple Range Test DRTWith a view to examining whether emotional stabilityinstability trait of personality would be influenced by certain the sex $\times$ employment variables a two way analysis of variance was performed on the scores of whether emotional stability-instability trait of personality. When Fratio obtained as a result of Anova, turned out to be significant statistically, further analysis was carried out using a multiple comparison test DRT, to study the 
significant difference and its directions on whether emotional stability-instability trait of personality.

\section{Results}

Table 2. The Anova Summary $(P<.05)$.

\begin{tabular}{llllll}
\hline Source of Variance & S.S. & df & M.S. & F & P \\
\hline Treatment & 845 & 7 & 120.8 & & \\
Employment Status & 665.70 & 3 & 221.9 & 10.82 & $<.01$ \\
Sex & 160.21 & 1 & 160.21 & 7.82 & $<.01$ \\
Employment Status $\times$ Sex & 19.69 & 3 & 6.56 & 0.32 & \\
Within Error & 3935.28 & 192 & 20.50 & & \\
Total & 4780.88 & 199 & & & \\
\hline
\end{tabular}

$F_{.05}(1,192)-3.89 ; F_{.05}(3,192)-2.65, F_{.01}(1,192)-6.76 ; F_{.01}(3,192)-3.88$.
Preliminary results indicated that a two way analysis of variance (ANOVA) with repeated measures on emotional stability-instability trait of personality score of male and female youth revealed significant main effect of employment status on emotional stability-instability trait of personality. Employment status was found to be highly significant.

The results indicate that main effect employment status and sex at .01 influence to emotional stability-instability trait of personality but the interaction between employment status $\times$ sex are not significant.

Table 3. Research Paradigm.

\begin{tabular}{lllllll}
\hline & & \multicolumn{2}{l}{ Employment Status } & & \\
\cline { 2 - 6 } & Fully Employed & Fully Unemployed & Seasonally Unemployed & Frictionally Unemployed & $\sum$ \\
\hline \multirow{2}{*}{ Sex } & Male & 170 & 258 & 144 & 176 & 748 \\
$\Sigma$ & Female & 221 & 303 & 164 & 239 & 927 \\
\hline
\end{tabular}

Effect of employment status is significant on emotional stability-instability trait of personality. Further distribution of effects on emotional stability-instability trait of personality of Employment status is determined with the help of DRT.

Table 4. DRT for multiple group comparison among employment status on emotional instability $v / s$ emotional stability trait of personality.

\begin{tabular}{lllllll}
\hline & A & B & C & D & E \\
\cline { 3 - 7 } & Seasonally Unemployed & Fully Employed & Frictionally Unemployed & Fully Unemployed & Shortest Significant Ranges \\
\hline & Means & 6.16 & 7.82 & 8.3 & 10.32 & \\
A & 6.16 & & 1.66 & 2.14 & 4.16 & R $2=1.77$ \\
B & 7.82 & & & 0.48 & 2.5 & R3 $=1.87$ \\
C & 8.3 & & & & 2.02 & R4 $=1.93$ \\
\hline
\end{tabular}

$\mathrm{Sx}-0.64, \mathrm{Xc}(192)-2.78,2.92,3.02$

Table 5. T-test between Employment Status and Sex.

\begin{tabular}{|c|c|c|c|c|c|c|}
\hline S.No. & $\begin{array}{l}\text { Variable } \\
\text { Status }\end{array}$ & Interaction & M & SD & $\mathbf{t}$ & $\mathbf{P}$ \\
\hline \multirow{2}{*}{ I } & \multirow{2}{*}{ Male } & Emp.Sta.Fully Emp. & 6.8 & 4.74 & \multirow{2}{*}{2.89} & \multirow{2}{*}{$<.01$} \\
\hline & & Emp.Sta.Fully Unemp. & 10.32 & 3.80 & & \\
\hline \multirow{2}{*}{ II } & \multirow{2}{*}{ Female } & Emp.Sta.Fully Emp. & 8.84 & 4.53 & \multirow{2}{*}{2.62} & \multirow{4}{*}{$<.01$} \\
\hline & & Emp.Sta.Fully Unemp. & 12.12 & 4.27 & & \\
\hline \multirow{2}{*}{ III } & \multirow{2}{*}{ Male } & Emp.Sta.Fully Emp. & 6.8 & 4.75 & \multirow{2}{*}{0.85} & \\
\hline & & Emp.Sta.Sea.Unemp. & 5.76 & 3.79 & & \\
\hline \multirow{2}{*}{ IV } & \multirow{2}{*}{ Female } & Emp.Sta.Fully Emp. & 8.84 & 4.53 & \multirow{2}{*}{2} & \\
\hline & & Emp.Sta.Sea.Unemp. & 6.56 & 3.41 & & \\
\hline \multirow{2}{*}{ V } & \multirow{2}{*}{ Male } & Emp.Sta.Fully Emp. & 6.8 & 4.75 & \multirow{2}{*}{0.18} & \\
\hline & & Emp.Sta.Fri Unemp. & 7.04 & 4.75 & & \\
\hline \multirow{2}{*}{ VI } & \multirow{2}{*}{ Female } & Emp.Sta.Fully Emp. & 8.84 & 4.53 & \multirow{2}{*}{0.49} & \\
\hline & & Emp.Sta.Fri.Unemp. & 9.56 & 5.75 & & \\
\hline \multirow{2}{*}{ VII } & \multirow{2}{*}{ Male } & Emp.Sta.Fully Unemp. & 10.32 & 3.80 & \multirow{2}{*}{4.26} & \multirow{2}{*}{$<.01$} \\
\hline & & Emp.Sta.Sea.Unemp. & 5.76 & 3.79 & & \\
\hline \multirow{2}{*}{ VIII } & \multirow{2}{*}{ Female } & Emp.Sta.Fully Unemp. & 12.12 & 4.27 & \multirow{2}{*}{5.05} & \multirow{2}{*}{$<.01$} \\
\hline & & Emp.Sta.Sea.Unemp. & 6.56 & 3.41 & & \\
\hline \multirow{2}{*}{ IX } & \multirow{2}{*}{ Male } & Emp.Sta.Fully Unemp. & 10.32 & 3.80 & \multirow{2}{*}{2.69} & \multirow{2}{*}{$<.01$} \\
\hline & & Emp.Sta.Fri.Unemp. & 7.04 & 4.75 & & \\
\hline \multirow{2}{*}{$\mathrm{X}$} & \multirow{2}{*}{ Female } & Emp.Sta.Fully Unemp. & 12.12 & 4.27 & 179 & \\
\hline & & Emp.Sta.Fri.Unemp. & 9.56 & 5.75 & & \\
\hline XI & Male & Emp.Sta.Sea.Unemp. & 5.76 & 3.79 & 106 & \\
\hline XI & Male & Emp.Sta.Fri.Unemp. & 7.04 & 4.75 & 1.00 & \\
\hline XII & Female & Emp.Sta.Sea.Unemp. & 6.56 & 3.41 & 2.24 & $<.05$ \\
\hline
\end{tabular}

\begin{tabular}{lllllll}
\hline S.No. & $\begin{array}{l}\text { Variable } \\
\text { Status }\end{array}$ & Interaction & M & SD & t & P \\
\hline \multirow{4}{*}{ XIII } & & Emp.Sta.Fri.Unemp. & 9.56 & 5.75 & & \\
& Emp.Sta.F & Male & 6.8 & 4.75 & \multirow{2}{*}{1.56} & \\
& ully.Emp. & Female & 8.84 & 4.53 & & \\
XIV & Emp.Sta.F & Male & 10.32 & 3.80 & \multirow{2}{*}{1.58} & \\
& ully.Unemp. & Female & 12.12 & 4.27 & & \\
XV & Emp.Sta.s & Male & 5.76 & 3.79 & \multirow{2}{*}{0.78} & \\
& ea.Unemp. & Female & 6.56 & 3.41 & & \\
XVI & Emp.Sta.F & Male & 7.04 & 4.75 & \multirow{2}{*}{1.69} & \\
& ri.Unemp. & Female & 9.56 & 5.75 & & \\
\hline
\end{tabular}

$\mathrm{t} .05(\mathrm{df}=48)=2.01 ; \mathrm{t} .01(\mathrm{df}=48)=2.68$

Fully unemployed are less emotionally stable than seasonally unemployed followed by fully employed and frictionally unemployed.

Fully Unemployed $>$ Seasonally Unemployed

Fully Unemployed $>$ Fully Employed

Fully Unemployed $>$ Frictionally Unemployed

Fully Unemployed $>$ Seasonally Unemployed followed by Fully Employed and Frictionally Unemployed

Full unemployment situation is capable to inculcate less emotional stability in youth than the seasonal unemployment following to frictional unemployment and full employment in youth. 
Frictionally unemployed youth are less emotional stable than seasonally unemployed youth.

Frictionally Unemployed > Seasonally Unemployed

Frictional unemployment situation is capable to inculcate less emotional stability in youth than seasonal unemployment in youth.

The results indicate that female youth are less emotional stable than male youth in general.

Although Employment Status and Sex is not significant. Further breakup of interaction results are as follows.

Results indicates that full unemployment in male youth promotes emotional instability than full employment. Full unemployment in female youth promotes emotional instability rather than full employment. Full unemployment in male youth promotes emotional instability rather than seasonal unemployment. Full unemployment in female youth promotes emotional instability rather than seasonal unemployment. Full unemployment in male youth promotes emotional instability rather than frictional unemployment. Frictional unemployment in female youth promotes emotional instability than seasonal unemployment.

\subsection{Graphical Presentation of Main Effect \& Interaction}
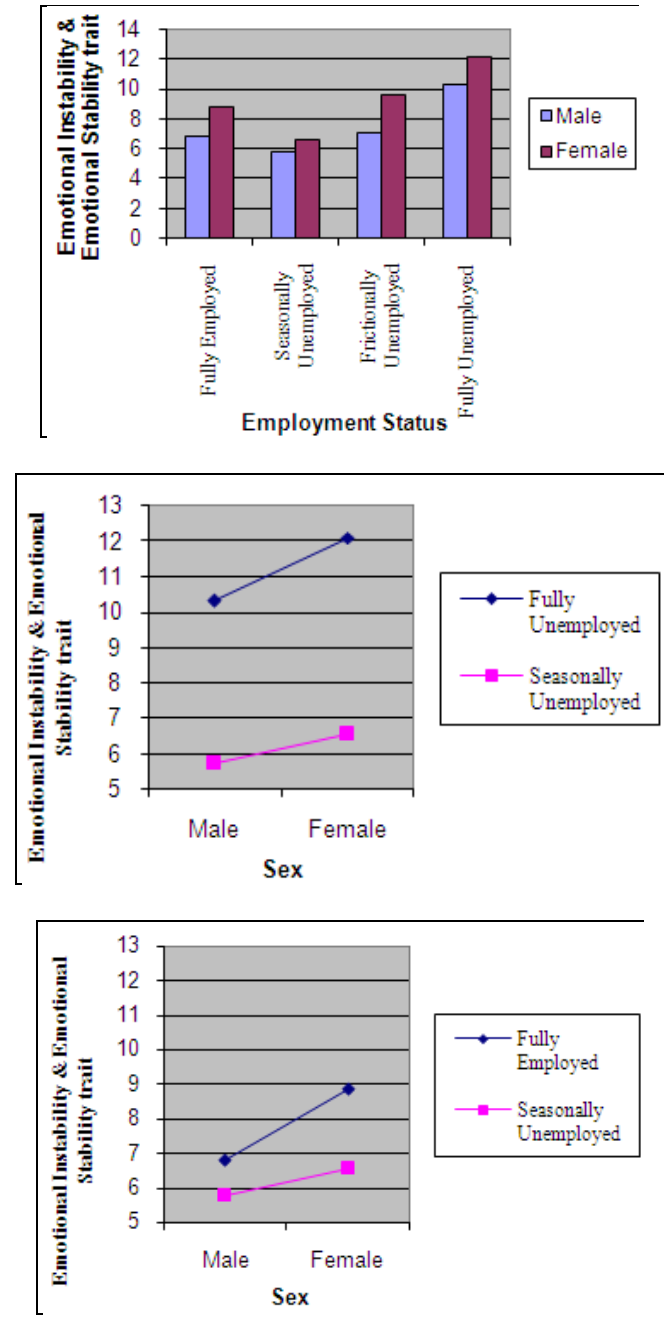

Graph 1. Emotional Instability \& Emotional Stability trait of Personality $=f$ Employment Status and Sex (Main Effect).
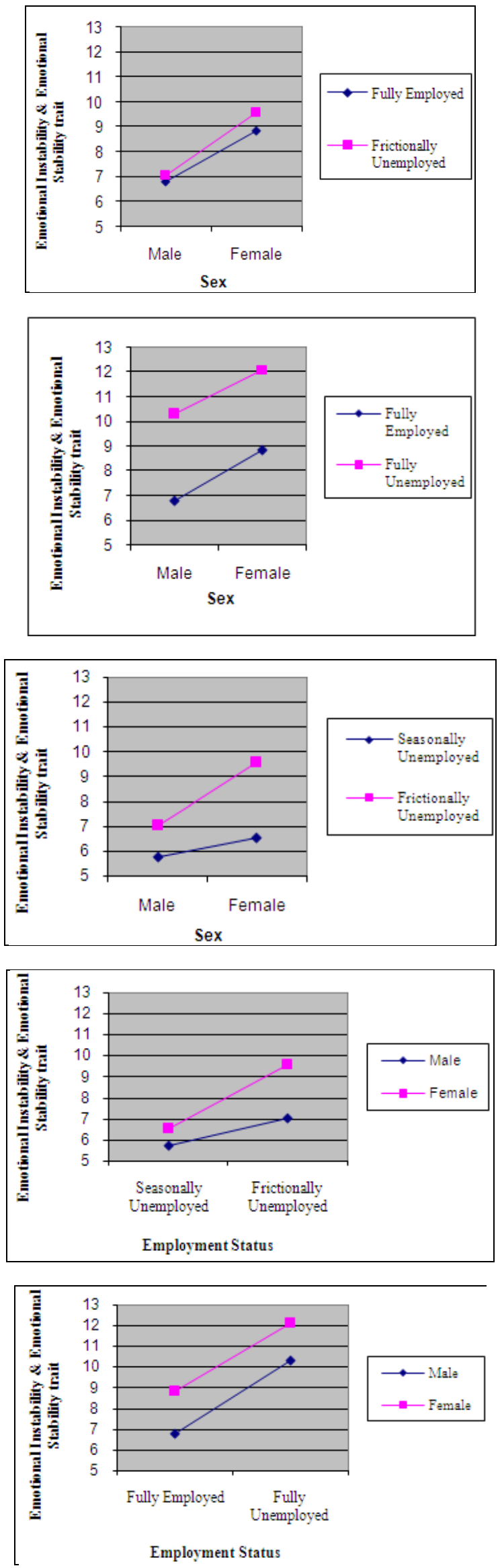


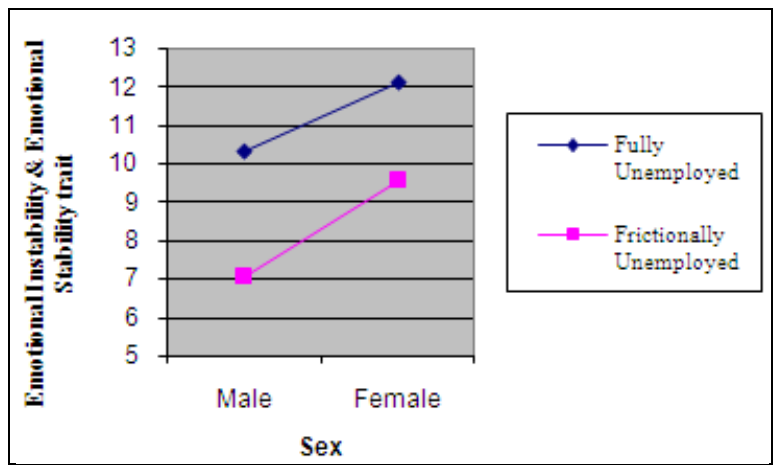

Graph 2. Emotional Instability \& Emotional Stability trait of Personality $=f$ Employment Status $\times$ Sex (Interaction).

\section{Discussion}

The study was supported by the findings of Hansson, Robert O. Briggs, Stephen R. Rule, Bonnie L. (1990) and Grossi, Giorgio Ahs, Anna Lundberg, Ulf (1998) who studied that the full unemployed youths are less emotional stable in compare to others.

Grossi, Giorgio (1999) supported the finding that full unemployed youths are less emotional stable in compare to others and female youths are less emotional stable than male youth in general.

McKee-Ryan et all (2005) support the finding that unemployed individuals had lower psychological and physical well-being than did their employed counterparts.

Brijesh Kumar Upadhayay, C. P. Khokhar (2006) also support the finding that enthusiastic unemployed youths feel less lonely than the non enthusiastic unemployed youths.

\section{Conclusions}

The full unemployment situation is capable to inculcate less emotional stable in youth than the seasonal unemployment following to frictional unemployment and full employment in youth. Frictional unemployment situation is capable to inculcate less emotional stable in youth than seasonal unemployment in youth. The results indicate that female youth are less emotional stable than male youth in general. Emotional Instability trait in their personality independent of sex effect is higher among the unemployed in comparison of employed. Emotional instability trait in their personality independent of sex effect is higher among fully unemployed in comparison of seasonally unemployed. In male youth full unemployment promotes emotional instability trait in their personality than male youth who are frictionally unemployed. In female youth frictional unemployment promotes emotional instability trait in their personality than those who are seasonally unemployed females.

\section{References}

[1] Bhargava, M., (1997). Dimensional personality inventory (DPI), Nandini Enterprisese, Agra, India.

[2] Upadhayay, B., Khokhar, C.(2006). Personality Traits And Feeling Of Loneliness In Unemployed Youths. Europe's Journal of Psychology, North America, 2, Nov. 2006. Available at: $<$ http://ejop.psychopen.eu/article/view/288>

[3] Grossi, Giorgio; Ahs, Anna; Lundberg, Ulf (1998)"Psychological correlates of salivary cortisol secretion among unemployed men and women", Integrative Physiological and Behavioral Science. Jul-Sep; Vol. 33(3): 249-263, US: Transaction Periodicals Consortium.

[4] Hansson, Robert O; Briggs, Stephen R; Rule, Bonnie L.(1990) "Old age and unemployment: Predictors of perceived control, depression and loneliness", Journal of Applied Gerontology, Jun; Vol. 9(2); 230-240, US: Sage Publications Inc.

[5] McKee-Ryan, F. M., Song, Z., Wanberg, C. R., \& Kinicki, A. J. (2005). Psychological and physical well-being during unemployment: A meta-analytic study. Journal of Applied Psychology, 90(1), 53-76.

[6] http://www.actionforex.com/articles-library/financialglossary/unemployment-types-20041209486/ 